\title{
A Role for Postsynaptic Neurons in Determining Presynaptic Release Properties in the Cricket CNS: Evidence for Retrograde Control of Facilitation
}

\author{
Graeme W. Davis and R. K. Murphey \\ Neuroscience and Behavior Program, University of Massachusetts, Amherst, Massachusetts 01003
}

Intracellular recordings in the cricket cercal system show that the synaptic terminals of a single sensory neuron can facilitate at one target, the medial giant interneuron (MGI), and simultaneously depress at another target, interneuron 10-3. A quantal analysis of transmission at these synapses demonstrates that facilitation and depression are properties of the presynaptic cell. For facilitating synapses contacting MGI, the mean quantal content $(m)$, determined from the probability of the failures, increases for the second EPSP, while the quantal size $(q)$ remains constant. Similarly, an analysis of depression for those synapses contacting 10-3 supports a presynaptic mechanism for depression. Since facilitation and depression are presynaptic and their expression at the synapses of a single, identified sensory neuron are correlated with the target interneuron, we conclude that these properties are regulated locally, at the synapse, possibly by an interaction with the postsynaptic cell.

[Key words: retrograde message, quantal analysis, synaptic facilitation, synaptic depression, central synapse]

It is generally accepted that the presynaptic cell determines the types of plasticity that are expressed by its synaptic terminals. This view is largely due to the demonstration that many forms of synaptic plasticity are known to be the result of changes in the release properties of the presynaptic terminal. For example, the presynaptic natures of short-term facilitation and depression were demonstrated using quantal analysis, both peripherally (Del Castillo and Katz, 1954; Mallart and Martin, 1968; Wernig, 1972; Zucker, 1973) and centrally (Hess et al., 1987; Lin and Faber, 1988). Similar techniques were used to determine the presynaptic nature of changes associated with long-term facilitation (Wojtowicz and Atwood, 1986; Dale et al., 1988) and long-term potentiation (Malinow and Tsien, 1990; Malinow, 1991; but see Manabe et al., 1992).

A growing body of evidence, however, supports the possibility that the postsynaptic cell may regulate the release properties of the presynaptic terminals that contact it. A retrograde determination of presynaptic release properties was originally sug-

\footnotetext{
Received Dec. 10, 1992; revised Mar. 8, 1993; accepted Mar. 16, 1993.

We thank Phyllis Caruccio for her technical support and for critical comments on the manuscript. We also thank Drs. Janis Weeks, Bill Roberts, Rick Levine, Akira Chiba, and Kathleen Killian as well as Andrew Hill for their comments on an earlier version of the manuscript. This work was supported by NSF Grant IBN91-21063 to R.K.M.

Correspondence should be addressed to Graeme Davis, Neuroscience and Behavior Program, Morrill Science Center (Biology), University of Massachusetts, Amherst, MA 01003.

Copyright (c) 1993 Society for Neuroscience $0270-6474 / 93 / 133827-12 \$ 05.00 / 0$
}

gested to occur at the crayfish neuromuscular junction (NMJ) (Atwood and Bittner, 1971; Frank 1973). Frank (1973) showed that facilitation differed at the terminals of a single motor neuron (MN) on different muscle fibers. Knowing that facilitation was a presynaptic phenomenon in that system, Frank hypothesized that individual muscle fibers determined the release properties of their presynaptic partners. A similar phenomenon has been proposed to exist in the CNS, at the sensory-motor synapses of the leech (Muller and Nicholls, 1974) and, more recently, at the Ia-MN synapses in cat spinal cord (Koerber and Mendell, 1991).

The cricket cercal sensory system provides unusually good resolution for the investigation of synaptic function within the CNS. The cercal sensory system consists of a population of sensory neurons (SNs) that project into the terminal abdominal ganglion, where they synapse with wind-sensitive interneurons (Bacon and Murphey, 1984; Shepherd et al., 1988). It is possible to identify uniquely and record from individual SNs while simultaneously recording from one or two identified postsynaptic interneurons. This allows us to characterize the population of SNs synapsing on identified postsynaptic cells, as well as examining single SNs that simultaneously contact two postsynaptic cells. In addition, favorable electrogeometry provides the resolution needed to perform a quantal analysis at these central synapses. Finally, the development of these SNs is well characterized, so we know the age and characteristic amplitude of each synaptic contact studied (Chiba et al., 1988). Taking advantage of these strengths, we present strong evidence for the presence of a retrograde influence on the release properties of presynaptic terminals at a central synapse.

\section{Materials and Methods}

Animals. Crickets (Acheta domesticus) were obtained from Flukers Cricket Farm (Baton Rouge, LA) between the first and third instars. Animals were kept in groups and reared to the adult stage at $29^{\circ} \mathrm{C}$ on a $12: 12 \mathrm{hr}$ light/dark schedule. Animals were provided dog food and distilled water ad libitum. Unless otherwise specified, female crickets between 6 and $24 \mathrm{hr}$ after adult eclosion were used.

Physiological methods. Specimens were anesthetized on ice for 30 $90 \mathrm{~min}$ prior to dissection. All experiments were performed at $18-20^{\circ} \mathrm{C}$. The preparation consisted of the isolated abdomen described by Shepherd and Murphey (1986).

Intracellular recordings were made from the soma of interneuron 10-3 and the large ventromedial dendrite of medial giant interneurons (MGIs) (Fig. 1). Electrodes were filled with $2 \mathrm{~m}$ potassium acetate and had resistances of 30-50 M $\Omega$. Interneurons MGI and 10-3 were identified by their characteristic position and response properties to sound (Bacon and Murphey, 1984). Initially, the dendrite of MGI was identified by placing a second electrode in MGI's soma. Once the position and response properties recorded from the dendrite were familiar to the experimenter, the MGI could be recognized from the dendritic recording alone. 
The activity of the SN was recordcd cxtracellularly, using methods similar to those of Bacon and Murphey (1984). An identified sensory hair was cut to approximately one-third its length and a saline-filled micropipette was placed over the hair (Fig. 1). The spontaneous activity of the SN could be blocked by passing hyperpolarizing current through the recording pipette. The $\mathrm{SN}$ could be stimulated reliably at frequencies as high as $200 \mathrm{~Hz}$ by passing short, $100-200 \mu \mathrm{sec}$, depolarizing current pulses through the recording pipette. All data were recorded in bridge mode using either an Axoclamp (Axon Instruments) or Getting (Getting Instruments) microelectrode amplifier.

In characterizing the short-term plasticity of identified synapses, two stimulation paradigms were used: (1) bursts of 10 stimuli delivered at 4-120 Hz, each burst separated by a minimum of $30 \mathrm{sec}$, and (2) pairs of stimuli delivered with an interstimulus interval (ISI) of $8-250 \mathrm{msec}$, each pair separated by a 5-15 sec intertrial interval (ITI).

Data collection. Data were collected and stored to disk using either a Nicolet series 440 digital storage oscilloscope or pCLAMP data acquisition software with a Tl- 1 analog-to-digital interface (Axon Instruments). EPSPs were measured manually with the cursor option of the Nicolet oscilloscope or the cursor option of pCLAMP software. All data collection and analysis, including all off-line signal averaging, were done using pCLAMP software.

Quantal analysis. We sampled and stored as many EPSPs as each preparation permitted, with a minimum sample size of 500 EPSPs. A paired-pulse paradigm was used to examine facilitation in MGI as described above, except with ITI of $250 \mathrm{msec}$. This short ITI reduced transmitter release as a result of synaptic depression. In addition, transmission was reduced by replacing normal saline $\left(5 \mathrm{mM} \mathrm{Ca}^{2+}, 0 \mathrm{~mm}\right.$ $\mathrm{Mg}^{2+}$ ) with a low-C $\mathrm{Ca}^{21}$ saline ( 0 Inm $\left.\mathrm{Ca}^{2+}, 40 \mathrm{~mm} \mathrm{Mg}^{21}\right)$. Under these conditions a high rate of failure was observed, and a significant pairedpulse facilitation was still present. In 10-3, homosynaptic depression was dramatically reduced under conditions of low release, and therefore analysis of depression in 10-3 was done under normal ionic conditions and an ITI of $1 \mathrm{sec}$. In all cases, data were analyzed over regions of stable transmitter release, as determined by comparing sequential averages of 100 consecutive EPSPs (Dale et al., 1988).

We measured all individual FPSPs by hand using the cursor option of pCLAMP software. Identification of evoked EPSPs for measurement was based on the latency of the EPSP following the stimulus artifact. A signal average for regions of 100-300 EPSPs was used as a template to determine the average latency of EPSP initiation and the approximate time-to-peak EPSP amplitude. Individual traces were then measured from the time of EPSP initiation, determined from the average EPSP latency, to the peak amplitude occurring in the region of the template peak amplitude. Measurements that fell into the distribution of presumed failures in the amplitude histograms were signal averaged to determine if any time-locked events existed in these traces.

Under conditions of low release it was assumed that the number of quanta released followed a Poisson distribution. An estimate of the mean quantal content $(m)$ was therefore obtained by a failure analysis where $m$ was determined by examining the ratio of failures $\left(n_{0}\right)$ to the total number of trials $(N)$. An estimate of $m$ was calculated as $m=\ln$ $N / n_{0}$. The mean quantal amplitude $(q)$ was then determined from $q=$ $E / m$, where $E$ is the avcragc EPSP amplitude (Martin, 1966).

\section{Results}

\section{Identification of individual SNS and their target interneurons}

Individual SNs were identified by the stereotypic length and location of their associated filiform sensory receptor (Shepherd et al., 1988). The activity of individual SNs was precisely controlled by placing a large-diameter electrode over the cut end of a sensory hair and passing current through the hollow shaft of the hair. Unitary EPSPs were recorded from the large ventromedial dendrite of MGI, near the site of synaptic input or from the soma of 10-3, which was also electrotonically close to the site of synaptic input (Fig. $1 B$ ). The EPSPs recorded from these interneurons in response to spontaneous activity in the $\mathrm{SN}$ occurred with a short and constant latency (Fig. 1C). Previous work demonstrated that these connections were monosynaptic (Shepherd and Murphey, 1986). Recordings from the soma of 10-3 had a slightly slower rise time and a slower decay rate (Fig. $1 D$ ) because of the electrotonic distance from the synapse. As a result of this moderate electrotonic filtering, EPSP amplitudes recorded in 10-3 were biased toward smaller values.

\section{Synaptic plasticity of synapses on MGI and 10-3}

We examined the modulation of synaptic transmission during repetitive stimulation and observed a striking difference in the properties of synaptic transmission at these two interneurons; the $\mathrm{SN}$ synapses on MGI facilitate while $\mathrm{SN}$ synapses on 10-3 depress (Fig. 2A,B). To examine short-term synaptic modulation we delivered stimulus trains of 10 pulses to the SNs at 100 $\mathrm{Hz}$. The EPSPs recorded in MGI facilitated, whereas EPSPs recorded in 10-3 showed rapid depression (Fig. 2C).

When stimulated at frequencies at or above $100 \mathrm{~Hz}$, successive EPSPs often occurred on the falling phase of the previous stimulus (Fig. 2). The degree to which this occurred was highly variable, depending on the rate of decay of individual EPSPs. Throughout this study EPSPs were measured from the site of EPSP initiation (arrows in Fig. $2 A 2, B 2$ ) to the peak of the EPSP. This method tended to underestimate synaptic facilitation and overestimate synaptic depression (Fig. 2A2,B2), but did not significantly affect the difference between facilitating and depressing synapses, reported below.

We further characterized the properties of transmission at these two interneurons by stimulating the SNs over a range of frequencies from 4-120 Hz using paired-pulse stimulation. SNs were stimulated with two pulses separated by ISIs ranging from 8 to $250 \mathrm{msec}$ (Fig. $3 A, B$ ). This range of stimulus frequencies was well within the physiological range of SN firing frequencies (Shimozawa and Kanou, 1984). We were limited to stimulation rates below $120 \mathrm{~Hz}$ because at higher frequencies the stimulus artifact obscured the peak of the evoked EPSP. Figure $3 C$ represents the frequency response characteristics of five separate SNs: $1 \mathrm{e}, 2 \mathrm{c}$, and $3 \mathrm{c}$ recorded in $10-3$ and $3 \mathrm{c}, 5 \mathrm{a}$, and $7 \mathrm{a}$ recorded in MGI. Each point on the graph is the average of 20-30 stimulus pairs and the lines connect data from individual $\mathrm{SNs}$ recorded in a single preparation. Stimulation at low frequencies (4-20 $\mathrm{Hz}$ ) caused moderate synaptic depression at both MGI and 103. However, stimulation at $100 \mathrm{~Hz}$ and above caused facilitation at the synapses recorded from MGI, but caused pronounced depression at synapses recorded from 10-3 (Fig. 3C).

We examined a population of identified synapses on each interneuron in order to determine whether the population of synapses on each target interneuron had the same response characteristics. We examined four SNs that contacted MGI and five SNs that contacted 10-3 during a total of 33 recordings. Each synaptic recording was examined at $100 \mathrm{~Hz}$. The mean modulation index (Inean fractional change in EPSP amplitude) was then determined for each recording. It was clear that nearly all the synaptic contacts recorded at MGI facilitate at this frequency, while nearly all the contacts at 10-3 show synaptic depression (Fig. 4).

The characteristic EPSP amplitude, determined as the average initial EPSP amplitude, varied for these synapses but was not related to the expression of facilitation or depression. The observed range of mean EPSP amplitudes recorded in MGI was $1.0-5.0 \mathrm{mV}$ and nearly every synapse showed facilitation. Similarly, the observed EPSP amplitudes at 10-3 ranged from 0.80 to $3.40 \mathrm{mV}$ and nearly every synapse showed synaptic depression (Fig. 4). Furthermore, we found no significant correlation between the degree of either facilitation or depression and the 


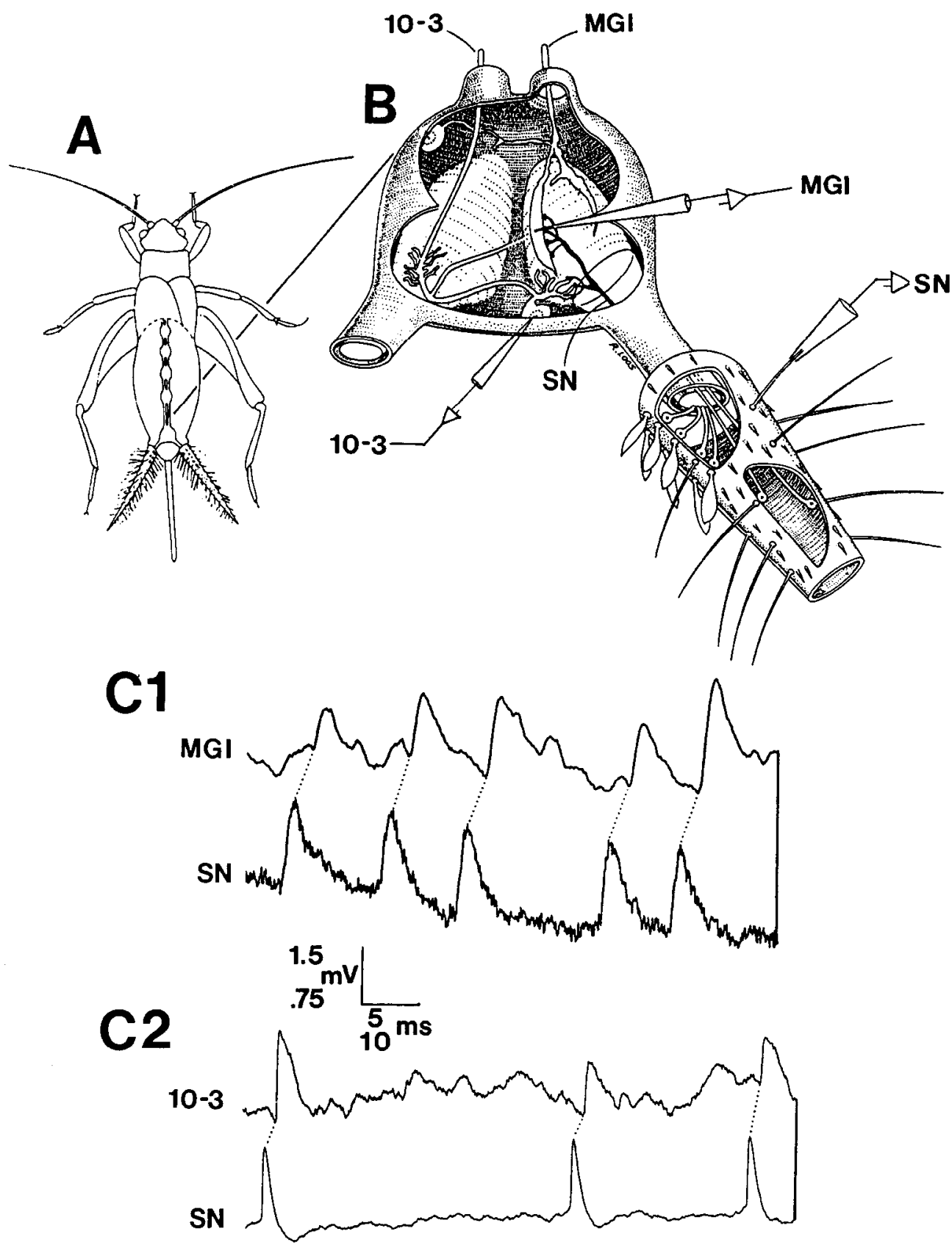

D<smiles>CCC=CCCCCCCCCCCCCCC</smiles><smiles>C=C(C)CCCCCC</smiles>

$\mathrm{mV}$
Figure 1. Synaptic connectivity in the cricket cercal sensory system. $A$, Dorsal view of a female cricket with the dorsal cuticle removed to expose the ventral abdominal nerve cord. $B$, Cutaway view of the terminal abdominal ganglion showing two wind-sensitive interneurons, MGI and 10-3, and the axonal projection of one of the SN studied here. An electrode placed over the cut end of a hollow filiform hair recorded SN action potentials. Each filiform hair and its associated $\mathrm{SN}$ were individually identifiable. Each SN was given a number that corresponds to its instar of birth and an arbitrary letter to distinguish $\mathrm{SNs}$ born in the same instar (Shepherd et al., 1988). SNs $2 \mathrm{c}$ and $3 \mathrm{c}$, examined in this study, contact both MGI and 10-3 in the region suggested by the diagram. Although shown as separate for clarity, the terminals of the SNs that contact both MGI and 10-3 are a continuum. Intracellular recording electrodes were placed in the large ventromedial dendrite of MGI and the cell soma of $10-$ 3 . The recording site in the ventromedial dendrite of MGI was very near the site of synaptic input. Note that the small dendrites of 10-3 ipsilateral to the soma, which receive input from the SNs examined in this study, were also electrotonically close to the somatic recording site. $C$, Sample recordings from MGI (C1, upper trace) and 10-3 (C2, upper trace) in response to spontaneous activity of a presynaptic filiform SN (lower traces). Each SN action potential was followed by an EPSP in the interneuron with a short and constant latency. $D$, Signal averaged EPSPs $(N=10)$ recorded in the dendrite of MGI and soma of 10-3 during stimulation of a single $\mathrm{SN}$, in different preparations. These traces were superimposed (MGI + 103 ), demonstrating the slower rise time of EPSPs recorded in the soma of 103. The stimulus artifacts have been indicated by asterisks and have been removed from the superimposed traces for clarity. 

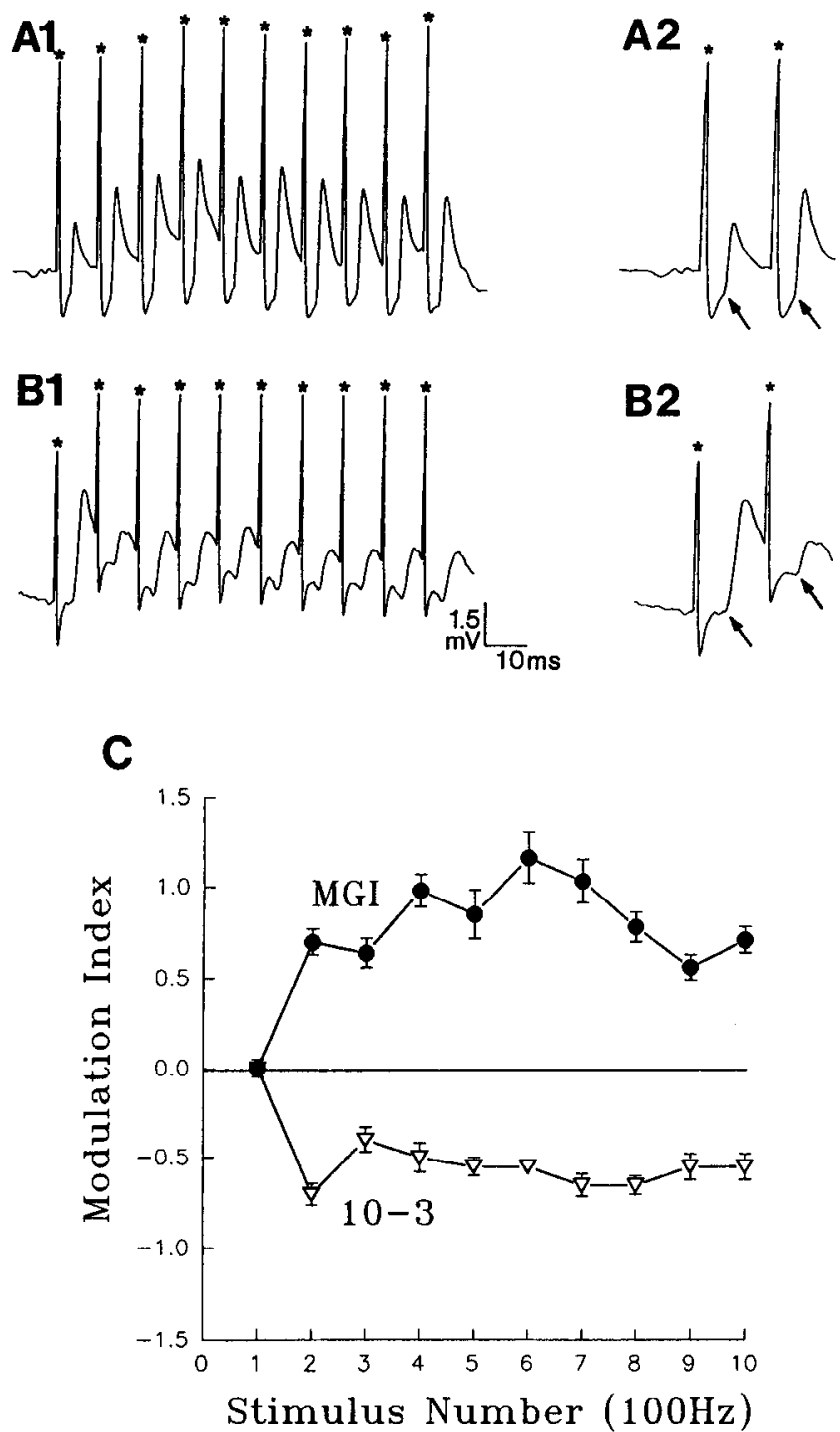

Figure 2. The plasticity of synapses on MGI and 10-3. A1, Average EPSPs recorded from the ventromedial dendrite of MGI during stimulation of SN 5a in bursts of 10 stimuli at $100 \mathrm{~Hz}$ (average of 10 trials). The average EPSP amplitude facilitates dramatically during the first five stimuli, and is then followed by a slow return toward baseline. $A 2$, The first two averaged EPSPs of $A I$ are shown at higher sweep speed to show the latency and onset of EPSP initiation. EPSPs are measured from the time of initiation (arrows) to the peak of the EPSP. This method tended to underestimate facilitation since the second EPSP often rides on the falling phase of the previous EPSP. The stimulus artifacts are labeled $\left.{ }^{*}\right)$. B1, A signal averaged recording from the soma of $10-3$ in response to stimulation of hair $2 \mathrm{c}$ at $100 \mathrm{~Hz}$. Synaptic depression is evident during the first two or three stimuli followed by a plateau of stable transmission. B2, EPSPs are measured as in $A 2$. This method tended to overestimate depression when the second EPSP occurred on the falling phase of the first EPSP. $C$, Quantified data for the trials shown in $A$ and $B$. Each point is the average of 10 trials of 10 pulses, delivered at $100 \mathrm{~Hz}$. The average EPSP amplitudes on the y-axis are normalized to the first EPSP amplitude and are expressed as the average fractional change in EPSP amplitude, where fractional change is calculated as (EPSP $n$ - EPSP1/EPSP1). The x-axis represents the stimulus number in the train, delivered at $100 \mathrm{~Hz}$.

mean initial EPSP amplitude in these adult specimens. In summary, all of the afferent synapses on a given interneuron had similar properties, in spite of the differences in the mean amplitude of the first EPSP (Table 1).
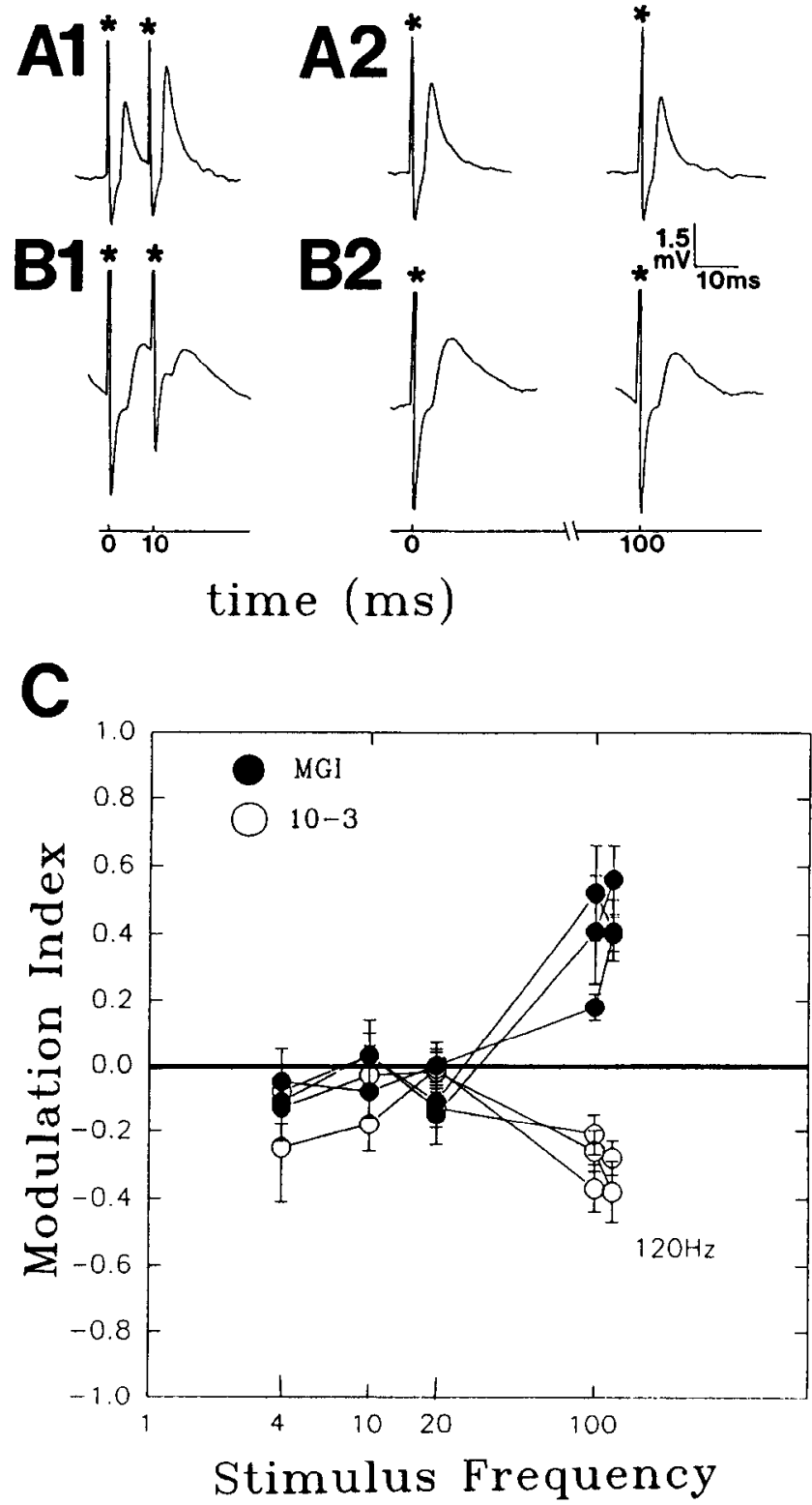

Figure 3. Frequency response of synapses on MGI and 10-3 differ. $A$, Recording from MGI in response to twin-pulse stimulation of SN 3c at 100 and $10 \mathrm{~Hz}$ instantaneous frequency. Facilitation is seen at 100 $\mathrm{H}_{z}(A 1)$, while moderate depression is observed at $10 \mathrm{~Hz}(A 2)$. Each trace is the signal average of 10 trials. Stimulus artifacts are labeled $\left(^{*}\right)$. $B$, Recording from $10-3$ in response to stimulation of $\mathrm{SN} 2 \mathrm{c} .10-3$ shows depression at $100 \mathrm{~Hz}$ stimulation $(B 1)$, as well as at $10 \mathrm{~Hz}(B 2)$. Again, each trace is the average of 10 trials. $C$, The stimulus paradigm shown in $A$ and $B$ is used to determine the modulation index for a number of identified SNs over a range of frequencies, $4-120 \mathrm{~Hz}$. The modulation index is calculated as in Figure 2. SNs recorded in MGI (solid circles) and 10-3 (open circles) show the same moderate synaptic depression during low-frequency stimulation at 4,10 , and $20 \mathrm{~Hz}$. During highfrequency stimulation, 100 and $120 \mathrm{~Hz}$, SNs contacting MGI facilitate while the SNs contacting 10-3 show synaptic deprcssion. Each point shows the mean and SE for 15-30 stimulus pairs. Points connected by a line are data from a single SN tested over the range of frequencies in a single preparation. Data are shown for SNs $7 \mathrm{a}, 5 \mathrm{a}$, and $3 \mathrm{c}$ recorded in MGI and for SNs $1 \mathrm{c}, 1 \mathrm{e}$, and $2 \mathrm{c}$ recorded in 10-3.

\section{Evidence for a postsynaptic regulation of presynaptic release properties}

Because the properties of the synapse were correlated with the postsynaptic cell, we hypothesized that the short-term plasticity 
of these synapses was being specified locally, at the synapses, by a retrograde signal from the postsynaptic interneuron. To test this idea we examined the synapses of SNs $2 \mathrm{c}$ and $3 \mathrm{c}$, each of which contact both MGI and 10-3 (Shepherd et al., 1988) (Fig. 5A). Much of the data for this experiment was collected in eighth instar animals where strong synaptic contacts were made by these SNs on both MGI and 10-3. By the adult stage the contact from SN 2c to MGI had been eliminated during a process of synaptic rearrangement (Chiba et al., 1988).

The synapses of single SNs simultaneously facilitated on MGI and depressed on 10-3. This is illustrated by representative simultaneous recordings from one $\mathrm{SN}$ and both interneurons (Fig. $5 B$ ). The mean facilitation indices show that single SNs are consistently capable of showing facilitation at one postsynaptic neuron, MGI, and depression at another postsynaptic neuron, 10-3 (Fig. 5C). The difference in facilitation indices was significant in seven of eight preparations (Fig. $5 C$ ). It should be noted that the difference in modulation indices using the two pulse method was an underestimation of the actual difference in release properties at the two interneurons since facilitation in MGI develops to a maximum after the first three to five stimuli (Fig. 2). The demonstration that single SNs facilitated on one target and simultaneously depressed at another target provides strong evidence for the hypothesis that presynaptic release properties are determined locally, at the synapses, possibly by an interaction with the postsynaptic target cell.

\section{Quantal analysis of synaptic modulation}

Facilitation. Facilitation is classically understood to be presynaptic, based primarily on quantal analysis (Del Castillo and Katz, 1954; Mallart and Martin, 1968; Wernig, 1972; Zucker, 1973). We therefore carried out a quantal analysis to demonstrate that facilitation is a presynaptic phenomenon at these central synapses.

The SN-to-MGI recording arrangement was well suited for quantal analysis at a central synapse. We were able to stimulate a single identified afferent reliably and EPSPs were recorded from the large ventromedial dendrite of MGI, very near the site of synaptic input. The EPSPs recorded in the dendrite of MGI were large and fast rising, and provided enough resolution to discriminate the failures from the unitary responses in the frequency histograms (Fig. 6A,B).

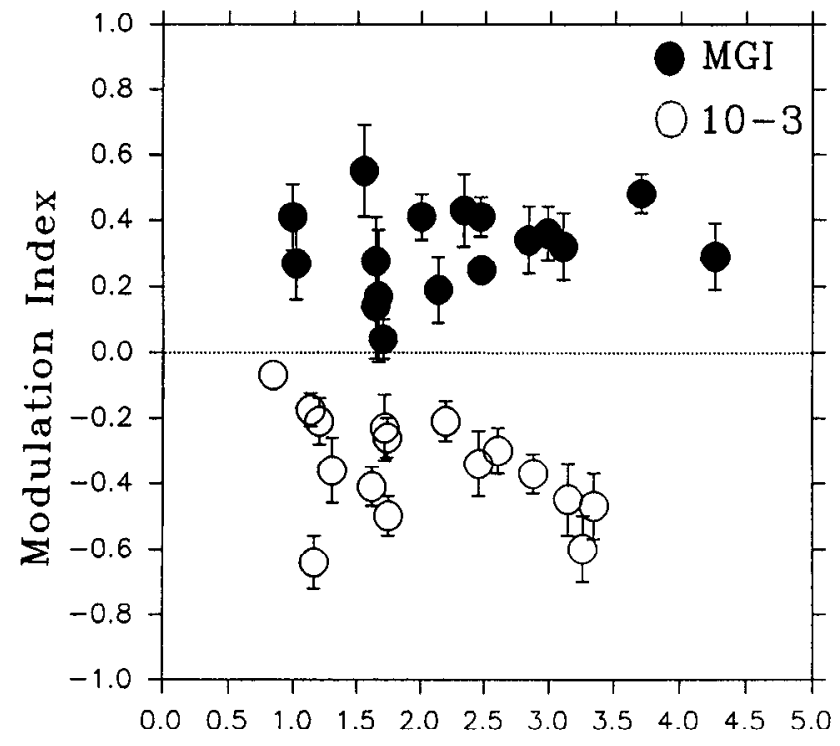

Avg Amplitude EPSP1 (mV)

Figure 4. Modulation indices are matched to the postsynaptic cell and are independent of mean initial EPSP amplitude. The modulation index is plotted against the mean initial EPSP amplitude for each stimulus pair. Data are shown for 17 recordings from MGI (solid circles). This sample includes SNs $3 \mathrm{c}(n=8), 2 \mathrm{~b}(n=2), 5 \mathrm{a}(n=4)$, and $7 \mathrm{a}(n=3)$. Data are shown for 16 recordings from 10-3 (open circles). This sample includes SNs $2 \mathrm{c}(n=9), 3 \mathrm{c}(n=2), 1 \mathrm{c}(n=2), 1 \mathrm{e}(n=2)$, and $1 \mathrm{f}(n=$ 1). Nearly all the contacts to MGI show significant facilitation, while nearly all those to 10-3 show significant depression. In addition, there is no correlation between the amplitude of the initial EPSP and the amount of facilitation recorded in MGI (solid circles). Similarly, there is no significant correlation between the initial EPSP amplitude recorded in 10-3 and the facilitation index (open circles) $(r=0.20)$. Facilitation and depression were induced by delivering paired stimuli to individual SNs at $100 \mathrm{~Hz}$ in adult animals. Modulation indices are calculated as in Figure 2.

In order to increase the failure rate of evoked EPSPs, so that a failure analysis could be applied, release was reduced by replacing the normal saline ( $5 \mathrm{mM} \mathrm{Ca}{ }^{2+}, 0 \mathrm{mM} \mathrm{Mg}^{2+}$ ) with $0 \mathrm{mM}$ $\mathrm{Ca}^{2+}, 40 \mathrm{~mm} \mathrm{Mg}^{2+}$ saline. Thirty minutes in this saline was often required before a substantial reduction in EPSP amplitude was seen. Even under these ionic conditions, however, the syn-

Table 1. Average modulation index (Index) and EPSP amplitude (EPSP1) for SNs stimulated at $100 \mathrm{~Hz}$

\begin{tabular}{|c|c|c|c|c|c|c|}
\hline \multirow[b]{2}{*}{ Hair } & \multicolumn{3}{|c|}{ MGI } & \multicolumn{3}{|c|}{$10-3$} \\
\hline & $N^{a}$ & $\begin{array}{l}\text { EPSP1 } \\
( \pm \text { SEM })\end{array}$ & $\begin{array}{l}\text { Index } \\
( \pm \text { SEM })\end{array}$ & $N^{a}$ & $\begin{array}{l}\text { EPSP1 } \\
( \pm \text { SEM })\end{array}$ & $\begin{array}{l}\text { Index } \\
( \pm \text { SEM })\end{array}$ \\
\hline $3 c$ & 11 & $2.38(0.43) \mathrm{mV}$ & $0.44(0.07)$ & 6 & $1.59(0.26) \mathrm{mV}$ & $-0.23(0.04)$ \\
\hline $5 a$ & 4 & $3.03(0.26) \mathrm{mV}$ & $0.34(0.05)$ & \multirow{2}{*}{\multicolumn{2}{|c|}{ Not tested }} & \\
\hline $7 \mathrm{a}$ & 3 & $1.77(0.11) \mathrm{mV}$ & $0.24(0.09)$ & & & \\
\hline $2 c$ & \multirow{4}{*}{\multicolumn{2}{|c|}{ Not connected }} & & 11 & $3.77(0.48) \mathrm{mV}$ & $-0.46(0.05)$ \\
\hline lc & & & & 2 & $2.33(0.46) \mathrm{mV}$ & $-0.39(0.09)$ \\
\hline le & & & & 2 & $1.82(0.09) \mathrm{mV}$ & $-0.38(0.09)$ \\
\hline If & & & & 1 & 0.87 & -0.49 \\
\hline
\end{tabular}

Data shown in this table were obtained during paired-pulse stimulation at $100 \mathrm{~Hz}$ instantaneous frequency. The modulation index (Index) was calculated as in Figure 2. The mean initial EPSP amplitude was calculated as the mean first EPSP amplitude for the stimulus pairs. All recordings were made in the adult cricket. In this data set sensory neurons were sampled for MGI and 10-3 separately.

a Ten to thirty stimulus pairs were measured in each preparation. 
Figure 5. Single SNs simultaneously facilitate at MGI and depress at 10-3. $A$, Schematic of the recording situation showing stimulation of a single $\mathrm{SN}$ and 10-3 (see Fig. 1 for details). $B$, Sample traces from simultaneous recordings of MGI and 10-3 during stimulation of SN 2c. A paired stimulus evokes EPSPs in both MGI and 10-3 with identical latencies. Note facilitation at MGI and depression at 10-3. The times of EPSP initiation (arrows) and stimulus artifacts $\left({ }^{*}\right)$ are labeled. $C$, Data demonstrating that single SNs [SN $2 \mathrm{c}(n=6)$ and $3 c(n=2)$ ] simultaneously facilitate at MGI and depress at 10-3. Each pair of black and white bars represents the average modulation index (mean \pm SEM) seen in MGI (solid bar) and 10-3 (open bar) during stimulation of a singlc $\mathrm{SN}$ in one preparation. Between 10 and 30 stimulus pairs were delivered to the $\mathrm{SN}$ in a given preparation. The difference in modulation indices for a single $\mathrm{SN}$ simultaneously contacting MGI and $10-3$ are significant in all but one ( $n s$, not significant) of the preparations (paired Student's $t$ test, $p<0.05$ ). All data for this figure were recorded in the eighth instar animal for SN 2c, where this afferent makes a strong contact to both MGI and 10-3. The synapses from SN $3 \mathrm{c}$ were studied in both the eighth instar and the adult $(a)$ simultaneous recording from MGI and
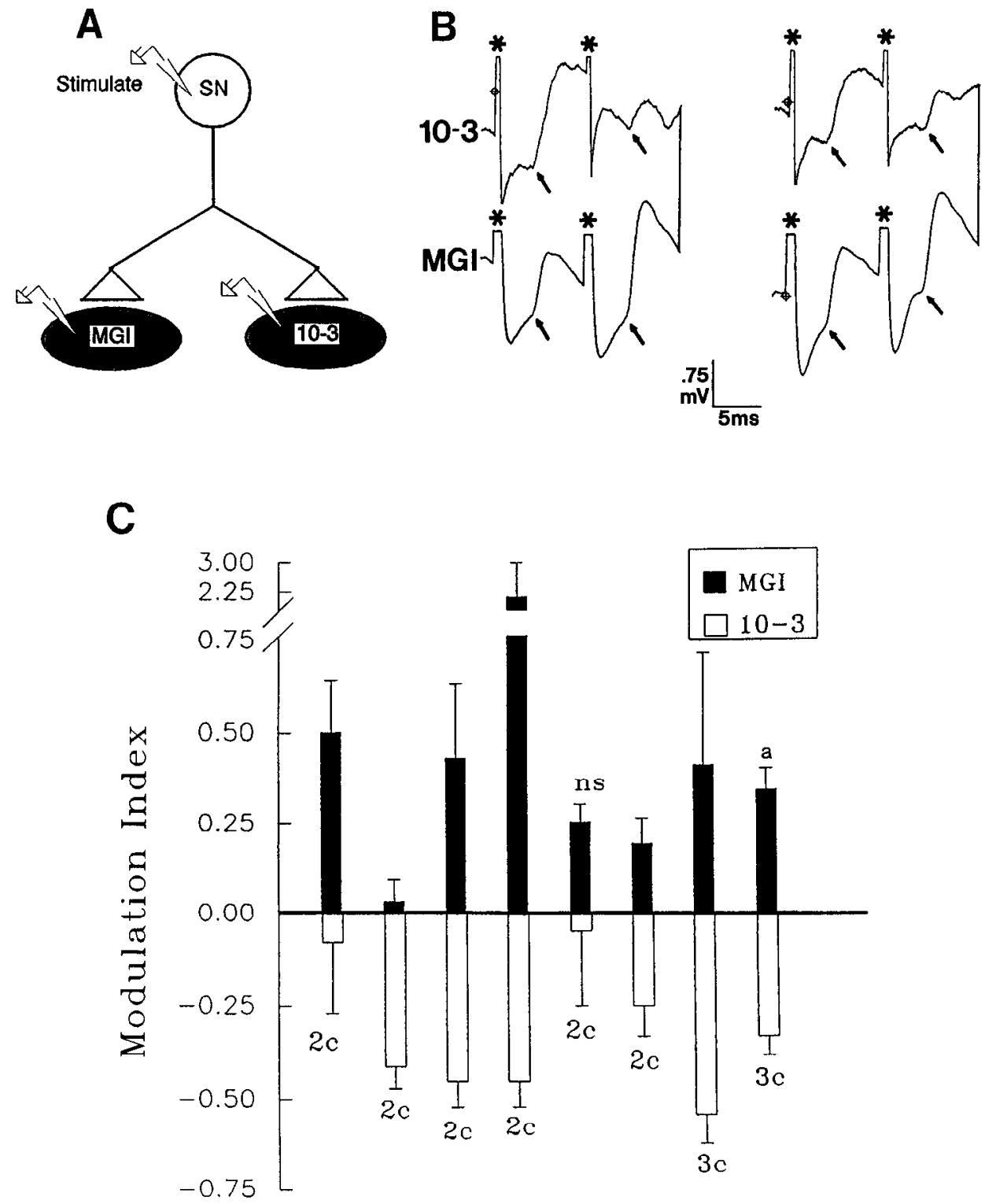

apses were rarely seen to fail. Therefore, to increase further the rate of failures, paired stimuli were delivered to the $\mathrm{SN}$ at 100 IIz, separated by an ITI of $250 \mathrm{msec}$. The short ITI further depressed transmission, causing an increase in the failure rate, and facilitation was still observed. A minimum of 500 F.PSPs were then analyzed for each preparation. These data were analyzed only over periods where transmission had reached a sta- ble "plateau region," determined by comparing the averages of consecutive groups of 100 EPSPs.

Amplitude histograms were constructed for the first and second stimulus-evoked EPSPs (Fig. 6A,B). Examination of the histograms demonstrated that the failures were clearly separated from the next peak in the histogram. When consecutive presumed failures were signal averaged, smaller time-locked release

Table 2. Failure analysis of facilitation at SN-to-MGI synapses

\begin{tabular}{|c|c|c|c|c|c|c|c|c|c|c|}
\hline \multirow[b]{2}{*}{ Prep. } & \multicolumn{5}{|c|}{ EPSP 1} & \multicolumn{5}{|c|}{ EPSP 2} \\
\hline & $\bar{N}$ & $n_{0}$ & $\vec{E}$ & $m$ & $\bar{q}$ & $\bar{N}$ & $n_{0}$ & $\bar{E}$ & $m$ & $q$ \\
\hline 1 & 1111 & 50 & 0.64 & 3.10 & 0.20 & 1081 & 2 & 1.01 & - & - \\
\hline 2 & 710 & 289 & 0.26 & 0.90 & 0.29 & 717 & 89 & 0.49 & 2.09 & 0.23 \\
\hline 3 & 837 & 484 & 0.14 & 0.55 & 0.25 & 830 & 206 & 0.31 & 1.39 & 0.22 \\
\hline
\end{tabular}

Data are shown for three preparations (Prep. 1-3) in which SN 3c was stimulated, where sufficient data were obtained for failure analysis of facilitation in MGI. Stimulus pairs were delivered to a single SN at $100 \mathrm{~Hz}$ and $250 \mathrm{msec}$ ITI. Values for the $m$ and $q$ are obtained by the failure method, calculating $m=\ln (N) / n_{0}$, where $N$ is the number of trials and $n_{0}$ is the number of failures. The average EPSP size, $\bar{E}$, is also shown. 

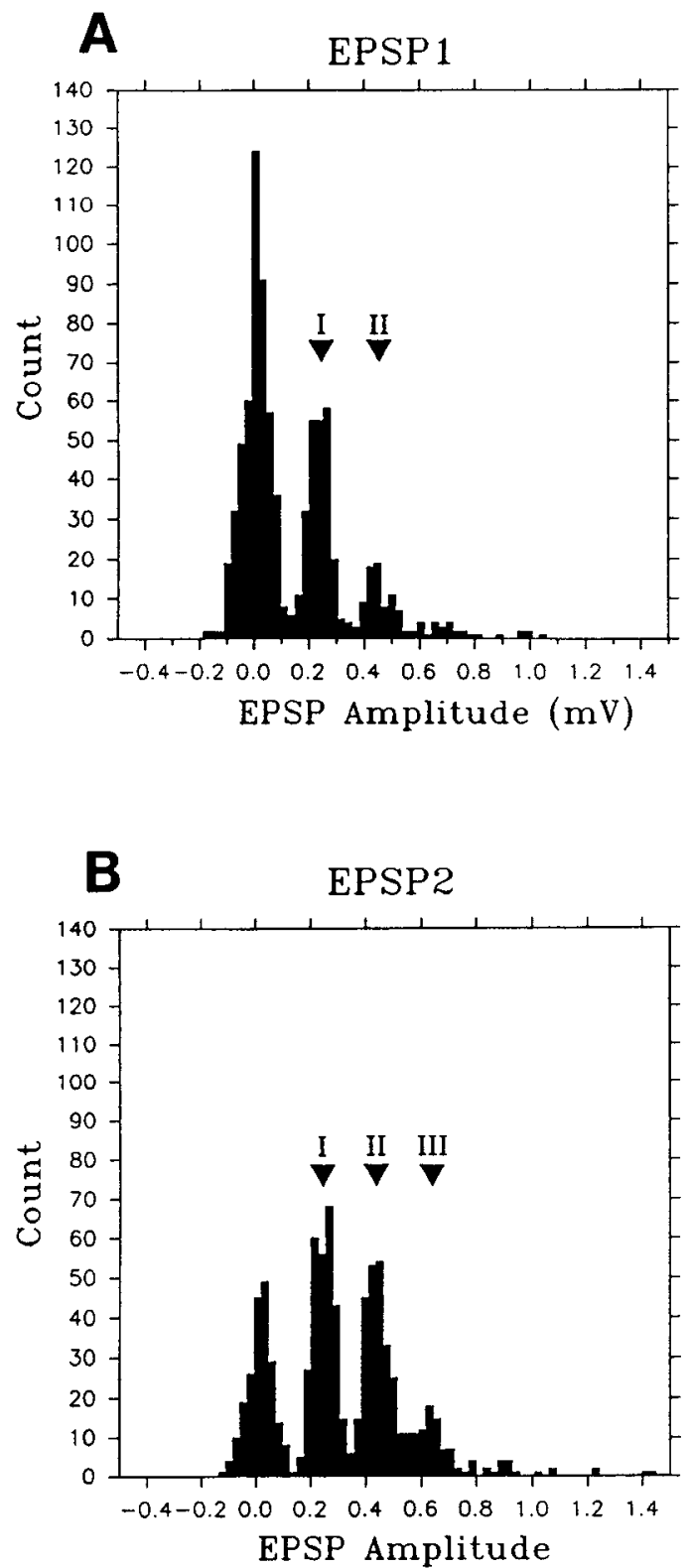
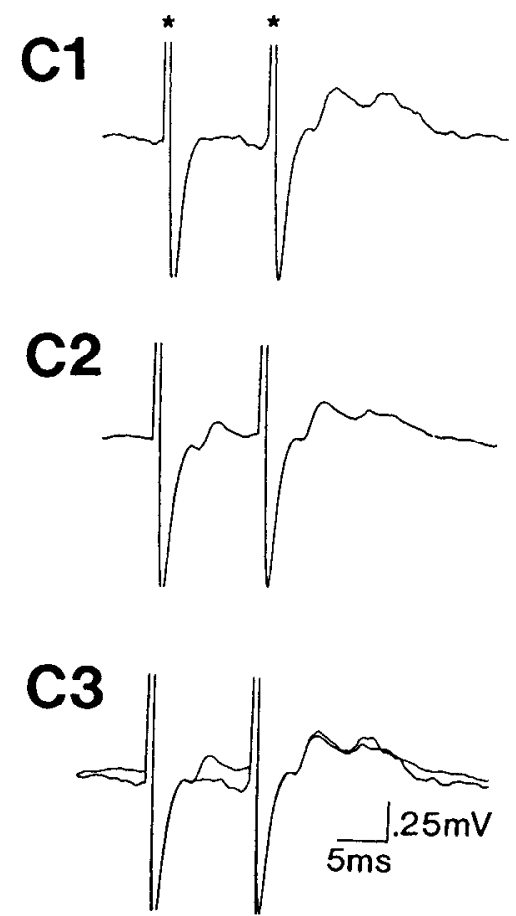

Figure 6. Quantal analysis supports a presynaptic mechanism for facilitation at the SN $3 \mathrm{c}$ to MGI synapse. EPSPs collected for quantal analysis in MGI are recorded during a period of constant transmission. To reduce transmission so that frequent failures to release transmitter are observed, paired stimuli at $100 \mathrm{~Hz}$ are delivered with a short ITI of $250 \mathrm{msec}$ that depresses transmitter release. All recordings are made in saline containing $0 \mathrm{mM} \mathrm{Ca}^{2+}, 40 \mathrm{~mm} \mathrm{Mg}{ }^{2+}$ to reduce transmitter release further. $A$, Amplitude histogram for the initial EPSPs (EPSPI). B, Amplitude histogram for facilitated second EPSPs (EPSP2). In $A$ and $B$, failures are distributed about zero and represent the initial peak in the histograms. Failures are clearly separated from the successive pcaks in the histograms (arrowheads $I, I I$, and $I I I)$. The number of failures $\left(n_{0}\right)$ decreased dramatically for the second EPSPs. The number of trials $(N)$ is 837 for EPSP 1 and 830 for EPSP2. A total of 900 paired stimuli were collected, of which a small number were discarded during measurement due to large spontaneous events which obscured the EPSP. Differences in the total number of discarded measurements account for the slight discrepancy in $N$ between the two histograms. When the $m$ and the $q$ are calculated by the failure method, $m$ increased for the EPSP2 distribution, from 0.55 to 1.39 , while $q$ remained constant, from 0.25 to 0.22 . $C 1$ is the average of 20 consecutive presumed failures during the first stimulus (EPSP1). The average does not reveal a smaller time-locked event. $C 2$ is the average of 200 consecutive traces spanning the 20 traces averaged in $C 1$. $C 3$ shows the averages of $C 1$ and $C 2$ superimposed. The superimposed traces demonstrate that the average second EPSP, following failure of EPSPl $(C l)$, is the same size as the average facilitated EPSP2 during trials where release occurred on the first trial (C2). A second potential, of unknown origin, appears in these averaged traces after EPSP2. This potential was highly variable. When it appeared it always occurred well after EPSP2 and therefore did not affect our measurements.

events were not revealed (Fig. $6 C 1$ ), indicating that no smaller release event existed.

Comparison of the two histograms (Fig. 6A,B) demonstrated that the number of failures decreased in the second EPSPs. When the $m$ was calculated by the failure method for the first and second EPSPs, it increased from 0.55 to 1.39 . This increase in $m$ can account for all of the increase in EPSP amplitude (Table 2). The increase in $m$ was accompanied by a constant $q$ of 0.25 $\mathrm{mV}$ and $0.22 \mathrm{mV}$, as calculated by $q=E / m$, where $E$ is the average EPSP amplitude. In addition, the prediction of $q$ by this method agreed well with the value of $q$ suggested by the separation of peaks in the amplitude histograms $(0.23 \mathrm{mV})$. Values 

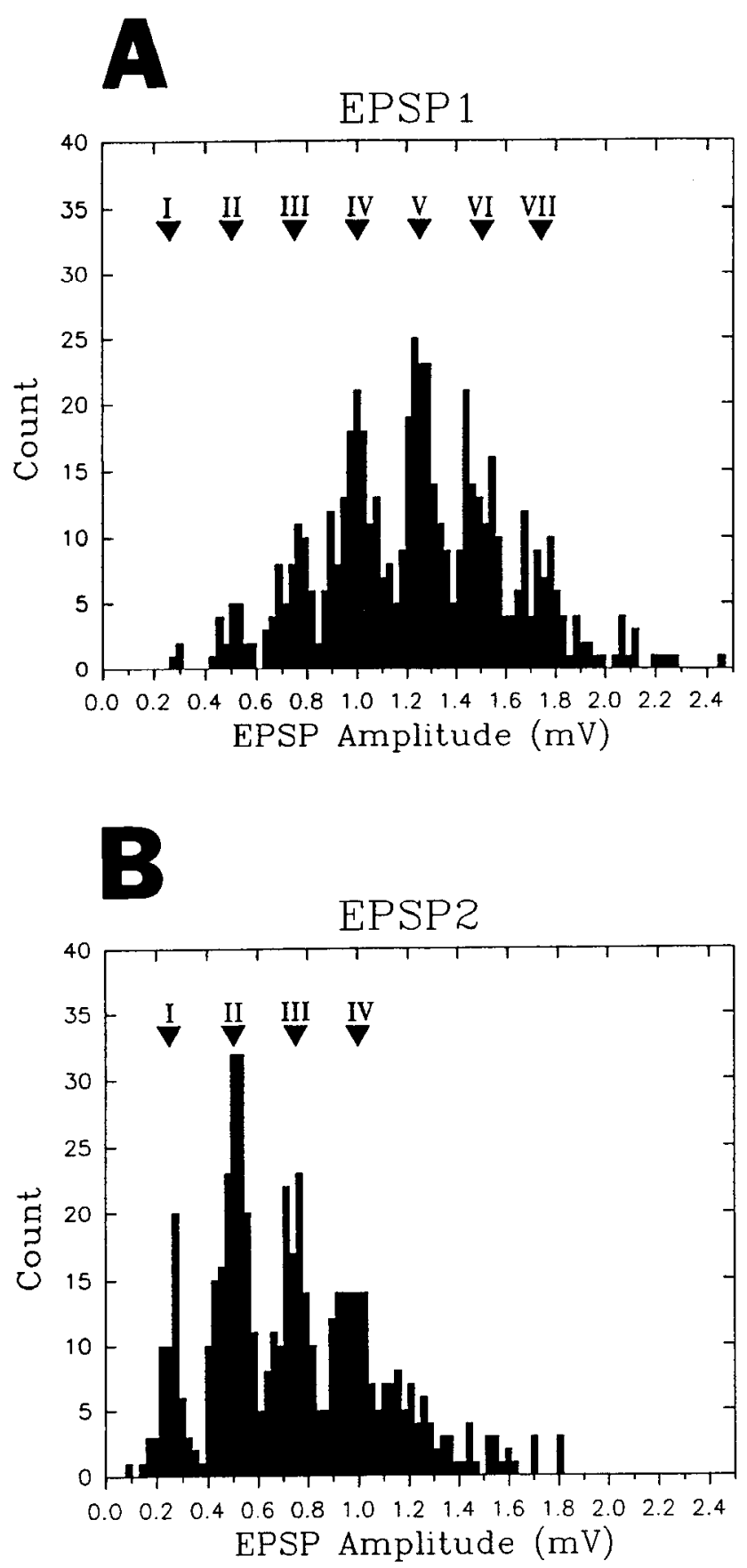

Figure 7. Evidence for a presynaptic mechanism for depression at the SN 2c-to-10-3 synapse. $A$, Amplitude histogram for the initial EPSPs (EPSP1). B, Amplitude histogram for the second, depressed, EPSPs of the stimulus pairs (EPSP2). Note the shift to the left in the histogram of second EPSPs. The average EPSP amplitude drops dramatically from $1.24 \mathrm{mV}$ for EPSP1 to $0.74 \mathrm{mV}$ for EPSP2. However, the position of the histogram peaks (arrowheads $I-V I I$ ) and the interpeak interval remain constant in $A$ and $B$, indicating that $q$ remains constant. A total of 600 paired stimuli were collected, of which a small fraction were discarded during measurement due to large spontaneous events that obscured measurement of the EPSP. This accounts for the discrepancy between the number of trials $(N)$ represented in each histogram. For EPSP1 $N=545$ and for EPSP2 $N=523$. for $m$ and $q$ calculated for two other preparations in which sufficient data were obtained are presented in Table 2 . In two of these preparations, the values for $m$ increased for the second EPSP while $q$ remained constant. In the remaining preparation, the levels of release were high and very few failures were observed in the facilitated second EPSPs. We therefore were unable to estimate $m$ and $q$ by the failure method. However, the number of failures clearly decreased in the EPSP2 distribution. In summary, these data supported a presynaptic mechanism for facilitation at the SN-to-MGI synapses.

One requirement of failure analysis is the ability to identify properly "true" failures to release transmitter in response to a presynaptic action potential. Misinterpretation could result if the smallest release events are inappropriately grouped as failures (Korn and Faber, 1991). A decrease in failures, such as that seen in the second EPSP distribution (Fig. 6B), could then be caused by an increase in $q$ rather than an increase in $m$. We discount this possibility for two reasons. First, averaging successive failures did not reveal a time-locked potential that would indicate a smaller release event that we have failed to detect (Fig. 6B). Second, the failures are clearly separated from the next peak in the histogram, by an interval equivalent to the calculated $q$.

Another possibility is that the failures we observe represent failure to stimulate the $\mathrm{SN}$ to fire an action potential, rather than failure of the $\mathrm{SN}$ to release transmitter. We were not able to visualize the afferent action potential because it was obscurcd by the stimulus artifact at the $\mathrm{SN}$ soma recording site. Furthermore, "en passant" recording of SN action potential was difficult due to spontaneous activity in the cercal nerve. However, we are confident that the responses grouped in the first peak of the histogram represent "true" failures of release, and not failure to activate the $\mathrm{SN}$, for the following reason. The averaged second EPSPs on those trials where release failed on the first stimulus is the same amplitude as the average facilitated second EPSP when release did occur on the first trial (Fig. 6C). This indicates that the averaged failures of the first EPSPs are true failures to release transmitter since facilitation requires that the terminal be invaded by an action potential. If failed first EPSPs had been due to failure of the action potential to invade the SN terminals, then the average second EPSP should have been closer to the size of the average first EPSP when release did occur.

The result that facilitation occurs following failure of the first EPSP (Fig. 6C) is independent evidence that facilitation is presynaptic. It demonstrates that facilitation occurs even when the postsynaptic cell has not been exposed to transmitter on the previous pulse, and therefore demonstrates that facilitation occurs without involvement of the postsynaptic cell.

Depression. Quantal analysis of depression was necessary to confirm that the differences in facilitation and depression at the terminals of a single cell reflected differences in presynaptic release properties. We recorded EPSPs from the soma of 10-3, which is electrotonically close to the site of synaptic input of SN 2c and 3c (Fig. 1 $A$ ). This favorable electrogeometry allowed us to record clear, fast rising EPSPs and, as a result, successive peaks in the amplitude histograms were clearly visible (Fig. 7).

The twin-pulse paradigm was again used to induce synaptic depression. However, significant depression was not observed under the conditions of low transmitter release described above for the analysis of facilitation (a low-Ca ${ }^{2+}$, high- $\mathrm{Mg}^{2+}$ saline and high-frequency ITI). Therefore, a failure analysis could not be 
applied to the synapses of 10-3. However, under normal ionic conditions it was possible to discriminate quantal variation in the amplitude of evoked EPSPs in 10-3. EPSPs were collected under normal ionic conditions with an $8 \mathrm{msec}$ ISI and $1 \mathrm{sec}$ ITI. EPSPs were analyzed only during periods of stable transmission.

When the first and second EPSP amplitude histograms were compared, a clearly defined interpeak interval of $0.25 \mathrm{mV}$ was maintained from the first to the second EPSPs, while the average EPSP amplitude decreased from $1.31 \mathrm{mV}$ to $0.60 \mathrm{mV}$ (Fig. 7). The constant $q$ suggested by the constant interpeak interval supported the conclusion that depression was a presynaptic process reflecting a reduction in the $m$. This result was consistent for two synapses at which enough data were obtained for analysis. These data supported the hypothesis that the properties of depression at the $\mathrm{SN}$-to-10-3 synapses is a presynaptic process.

\section{Discussion}

Three main results support the hypothesis that, in the cricket cercal sensory system, facilitation and depression are determined locally at the synapse, through an interaction with the postsynaptic cell (Fig. 8). First, we show through quantal analysis that facilitation and depression at central synapses are both presynaptic phenomena. Second, single SNs are capable of making synapses that facilitate on one postsynaptic neuron and simultaneously depress on another postsynaptic neuron. Third, the population of SNs that synapse with a given interneuron all exhibit similar properties of facilitation or depression.

\section{Quantal analysis at a central synapse}

Facilitation is presynaptic. A demonstration that facilitation in the cricket is presynaptic is essential to the hypothesis that the postsynaptic cell determines the release properties of the presynaptic terminal. Facilitation has been shown, through quantal analysis, to be a presynaptic phenomenon at both central (Kuno, 1964; Hess et al., 1987; Lin and Faber, 1988) and peripheral (Del Castillo and Katz, 1954; Mallart and Martin, 1968; Wernig, 1972; Zucker, 1973) synapses.

Quantal analysis at central synapses is difficult because it is impossible to recognize spontaneous miniature end-plate potentials belonging to the synapse under study (for review, see Korn and Faber, 1991). This is also true for the cricket CNS. However, we are able to achieve unusually good resolution by recording from the large dendrites of $\mathrm{MGI}$, very near the site of synaptic input while stimulating a single SN. This allows us to resolve peaks clearly in the histograms of EPSP amplitudes (Fig. 6A). In addition, failures of transmission are readily detected because the unit amplitude is well above the noise level (Fig. 6C). Therefore, if we assume a Poisson distribution for EPSP collected under conditions of low release, we can estimate the $m$ and the $q$ by analysis of the probability of failures.

The quantal analysis of paired-pulse facilitation in MGI clearly supports a presynaptic mechanism for short-term facilitation. The average EPSP amplitude increased for the second EPSPs, while the number of failures decreased. When $m$ was calculated by the failure method, $m$ increased for the second EPSPs while $q$ remained constant (Table 2). This was true at two of three synapses for which this analysis was done. In the third preparation, the number of failures was reduced to near zero in the second EPSPs and therefore estimates of $m$ and $q$ could not be made by the failure method. However, the facilitated EPSP

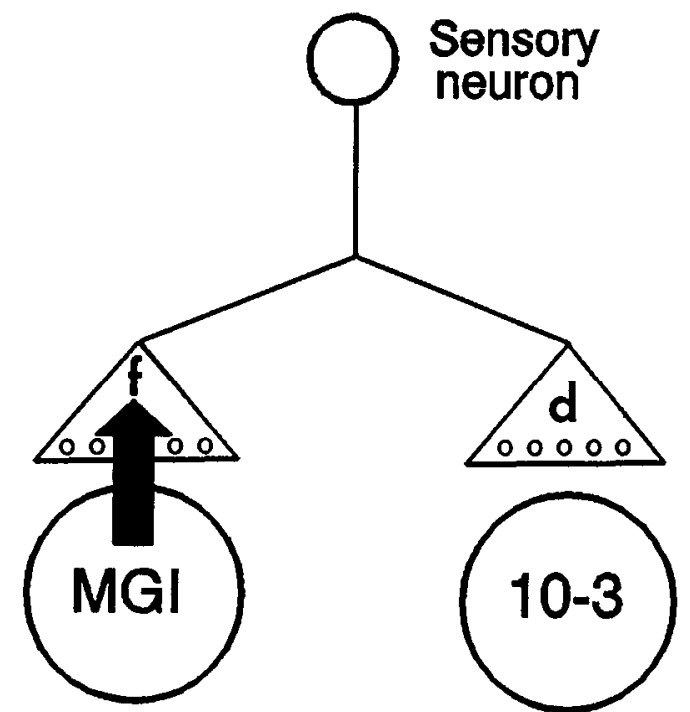

Figure 8. A retrograde cue from MGI regulates the release properties of its presynaptic terminals to express facilitation. We hypothesize that during development the SNs of the cricket have as their default option the ability to make synapses that express homosynaptic depression $(d)$. MGI and other similar interneurons are able to modify their presynaptic terminals through a retrograde signal (arrow) to express facilitation $(f)$. Therefore, a single $\mathrm{SN}$ is capable of making synapses that simultaneously facilitate on MGI and depress on 10-3.

amplitude was accompanied by a decrease in failures, as would be expected for a presynaptic mechanism of facilitation

Finally, the result that facilitation of the sccond EPSP occurs in trials where the first EPSP fails is further evidence that facilitation is presynaptic (Fig. 6C). Facilitation develops even when the postsynaptic cell has not been exposed to transmitter released on the first stimulus. Therefore, postsynaptic mechanisms for paired-pulse facilitation such as an increased receptor sensitivity or increased postsynaptic input resistance can be discounted.

Synaptic depression is presynaptic. Depression has been shown to be presynaptic based on a quantal analysis of transmission, both peripherally (Del Castillo and Katz, 1954) and centrally (Castellucci and Kandel, 1974; Korn et al., 1984). In order to support our hypothesis that synaptic release properties are determined at the synapse, it is necessary to show that depression is also presynaptic, and not a property of the postsynaptic cell that could mask the presence of presynaptic facilitation.

A failure analysis of depression at the synapses on 10-3 was not possible because depression was greatly reduced under conditions of low release. However, when paired-pulse depression was examined under normal release conditions (normal saline, stimulation rate of $1 \mathrm{~Hz}$ ), the data were consistent with a presynaptic mechanism for depression. The average EPSP amplitude decreased dramatically for the second EPSPs, while the $q$, estimated as the mean separation between successive peaks in the amplitude histogram, remained constant (Fig. 7).

\section{Evidence for postsynaptic regulation of presynaptic plasticity}

Since single SNs are capable of facilitation at one target, MGI, and depression at another target, 10-3 (Fig. 5), and since facilitation and depression are presynaptic processes, the terminals from a single SN must have different release properties on MGI and $10-3$. It seems likely, therefore, that the release properties 
of each individual synaptic site are determined locally, by an interaction with the postsynaptic cell.

The presence of a retrograde cue was further suggested by the observation that all the SN contacts examined at MGI facilitated, while all those at 10-3 depressed. If a retrograde cue, originating from the postsynaptic cell, was capable of modifying presynaptic terminals, then all the synapses on that cell should be similarly affected. We demonstrated that an identified SN always facilitated on MGI and that a sample of SNs of different ages that contact MGI all facilitated. The same was true for synapses showing depression at 10-3 (Fig. 4, Table 1).

Based on these observations, we hypothesize that synapses in the cercal system have as their default option the ability to express synaptic depression, and that a retrograde cue from MGI, and other similar interneurons, is required to modify presynaptic terminals to express facilitation (Fig. 8). The majority of SN connections in the cricket and locust systems, including some filiform SNs examined here and campaniform SNs in cricket (Killian and Murphey, 1992) and locust (N. Emptage, personal communication), show homosynaptic depression. In contrast, the sensory synapses on MGI and some sensory synapses in the moth (Weeks and Jacobs, 1987) are unusual in their ability to facilitate. We suggest that the synapses on MGI have been modified by an interaction with the postsynaptic cell to express facilitation (Fig. 8, arrow). The possibility that facilitation may be "added" to a synapse is supported by studies where the development of synaptic plasticity has been tracked through development. In these studies, young synapses exhibit homosynaptic depression, and frequency-dependent facilitation and potentiation emerge as separate processes later in development (Ohmori et al., 1981; Rayport and Camardo, 1984; Pawson and Chase, 1988).

The presence of a postsynaptically derived cue that determines the properties of facilitation was originally suggested for the PNS, at the lobster NMJ. It was shown that MNs expressed different levels of facilitation on different muscle fibers (Atwood and Bittner, 1971; Frank, 1973). Frank demonstrated that facilitation at these synapses was a presynaptic phenomenon and therefore proposed that the postsynaptic cells retrogradely determined the levels of facilitation expressed by the presynaptic terminals (Frank, 1973).

It has also been suggested that a retrograde control of facilitation occurs at central synapses. In the leech sensory-to-MN synapses, different levels of facilitation were expressed by a single SN on different target MNs (Muller and Nicholls, 1974). In the cat, it was demonstrated that single Ia afferents were capable of making synapses that facilitated on some target cells and depressed on others (Koerber and Mendell, 1991). The analysis at both these central synapses, however, does not show that the different plasticities at the terminals of a single $\mathrm{SN}$ represent presynaptic difference in transmitter release properties.

\section{Potential mechanisms for a retrograde determination of presynaptic facilitation}

There are at least two general mechanisms by which postsynaptic cells might modulate the function of presynaptic cells. Presynaptic terminals might receive a signal at the time of synaptogenesis and be immediately irreversibly modified for the life of the synapse. Alternatively, the postsynaptic cell may continually regulate the properties of synaptic plasticity expressed by the presynaptic terminals (Frank, 1973). We favor the latter possibility because cercal sensory synapses are being continually rearranged during development (Chiba et al., 1988). Since these synapses are being continually made and broken, we presume that the synaptic constituents and properties must be constantly "updated." A variation on this idea in hemimetabolous insects is that the synapses are intermittently adjusted. Each time the animal molts, a variety of well-characterized hormonal cues lead to the shedding of the old cuticle and the production of a new cuticle, as well as addition of a new subset of receptors (Gnazy and Roper, 1980; Levine and Truman, 1982). It is possible that the effects of a retrograde message may be limited to some critical time during these hormonal surges.

The nature of the retrograde message is unknown but proposed retrograde signals in other systems suggest the types of signaling that may be involved. Retrograde signals that affect properties of the presynaptic cell can include membrane or matrix bound molecules, as well as diffusible molecules released from the target cell or tissue (for review, see Landis, 1990). A potential retrograde messenger that has received considerable attention is nitric oxide (NO) (for review, see Brendt and Snyder, 1992; Fazeli, 1992). In the hippocampus it is thought that emission of NO from the postsynaptic cell can modulate the release properties of presynaptic terminals (Odell et al., 1991). NO may act on a number of processes in the presynaptic terminal, including stimulation of soluble guanylate cyclase and ADP-ribosyltransferase, which may in turn modulate the presynaptic release mechanism (Odell et al., 1991).

Numerous properties of the presynaptic terminal could be altered to modulate presynaptic facilitation. Since facilitation is generally thought to be a calcium-dependent phenomena of the presynaptic terminal (Katz and Miledi, 1968; Rahamimoff, 1968; Zucker, 1973), any component of the presynaptic terminal affecting presynaptic calcium levels would also be a potential target for the proposed retrograde message. $\mathrm{Ca}^{2+}$ influx, and therefore intraterminal $\mathrm{Ca}^{2+}$ levels, could be altered by modulating presynaptic, voltage-sensitive, $\mathrm{Ca}^{2+}$ channels directly, or by changing the shape of the presynaptic action potential by modulating voltage-sensitive $\mathrm{K}^{+}$channels (Keyser and Alger, 1990; Fazeli, 1992). Aspects of the $\mathrm{Ca}^{2+}$-coupled transmitter release mechanism may also be a target for a retrograde message affecting presynaptic release properties (Zoran et al., 1991).

Structural differences in the synapses might also be induced by the retrograde message. At the lobster NMJ, the terminals of a single $\mathrm{MN}$ showed facilitation on one target muscle and depression at another target muscle (Katz et al., 1993). The terminals that showed facilitation had fewer presynaptic dense bars and fewer instances of multiple dense bars at a single terminal than did the terminals from the same $\mathrm{MN}$ that showed synaptic depression. In the CNS, synapses on pyramidal cells that depress have a higher density of vesicular clustering at active zones when compared to synapses that show facilitation. This clustering may prevent the residual calcium accumulation responsible for facilitation (Bower and Haberly, 1986).

\section{Functional significance of postsynaptic control of presynaptic plasticity}

A retrograde control of presynaptic release properties may have evolved in cases where it was necessary for the postsynaptic cell to receive homogeneous input from a number of presynaptic cells. At the lobster NMJ, Frank proposed that individual muscle fibers determine the degree of presynaptic facilitation, there- 
by matching excitation-contraction coupling properties of the fiber to presynaptic input (Frank, 1973). A similar postsynaptic control of facilitation was proposed in leech to control the sequential recruitment of identified MNs. In this case, the highly facilitating synapses first recruited one MN controlling annulus erection, and then the poorly facilitating synapses recruited another MN that controlled shortening of the animal. A single SN thus controlled the sequential emergence of two behaviors (Muller and Nicholls, 1974; also see discussion, Koerber and Mendell, 1991).

In the cricket cercal system, MGI and 10-3 have different response properties. MGI responds phasically while 10-3 responds tonically to a given sensory stimulus (Kanou and Shimozawa, 1984; Chiba et al., 1992). It is thought that MGI encodes phasic sensory information while 10-3 encodes lonic information. Recent work shows that the response properties of interneurons MGI and 10-3 remain constant throughout postembryonic development (Kanou et al., 1988; Chiba et al., 1992). This is true despite the continual addition of synapses from new SNs to MGI with each instar, and the systematic rearrangement of SNs from MGI to 10-3 as SNs increase in age (Chiba et al., 1988; Kanou et al., 1988). The ability of the postsynaptic interneuron to determine retrogradely the properties of presynaptic relcase could function to maintain the properties of the postsynaptic cell as phasic or tonic.

The presence of such retrograde cues in systems as different as the crustacean NMJ, cricket sensory synapses, and cat IaMN synapses suggests that this may represent a general mechanism for controlling the development and function of synaptic circuits.

\section{References}

Atwood HL, Bittner GD (1971) Matching of excitatory and inhibitory inputs to crustacean muscle fibers. J Neurophysiol 34:157-170.

Bacon JP, Murphey RK (1984) Receptive fields of cricket giant interneurons are related to their dendritic structure. J Physiol (Lond) 352:601-623.

Bower JM, Haberly LB (1986) Facilitating and non-facilitating synapses on pyramidal cells: a correlation between physiology and morphology. Proc Natl Acad Sci USA 83:1115-1119.

Brendt DS, Snyder SH (1992) Nitric oxide, a novel neuronal messenger. Neuron 8:3-11.

Castellucci VF, Kandel ER (1974) A quantal analysis of the synaptic depression underlying habituation of the gill-withdrawal reflex in Aplysia. Proc Natl Acad Sci USA 71:5004-5008.

Chiba A, Shepherd D, Murphey RK (1988) Synaptic rearrangement during postembryonic development in the cricket. Science 240:901905.

Chiba A, Kamper G, Murphey RK (1992) Response properties of interneurons of the cricket cercal sensory system are conserved in spite of changes in peripheral receptors during maturation. J Exp Biol 164:205-226.

Dale N, Schacher S, Kandel ER (1988) Long-term facilitation in Aplysia involves increase in transmitter release. Science 239:282-284.

Del Castillo J, Katz B (1954) Statistical factors involved in neuromuscular facilitation and depression. J Physiol (Lond) 124:574-585.

Fazeli MS (1992) Synaptic plasticity: on the trail of the retrograde messenger. Trends Neurosci 15:115-117.

Frank E (1973) Matching of facilitation at the neuro-muscular junction of the lobster: a possible case for influence of muscle on nerve. $J$ Physiol (Lond) 233:635-658.

Gnazy W, Roper F (1980) Morphogenesis of mechanoreceptor and epidermal cells of crickets during the last instar, and its relation to molting-hormone level. Cell Tissue Res 213:369-391.

Hess G, Kuhut U, Voronin LL (1987) Quantal analysis of paired pulse facilitation in guinea pig hippocampal slices. Neurosci Lett 77:187192.
Kanou M, Shimozawa T (1984) A threshold analysis of cricket cercal interneurons by an alternating air-current stimulus. J Comp Physiol [A] 154:357-365.

Kanou M, Osawa T, Shimozawa T (1988) Ecdysial growth of the filiform hairs and sensitivity of the cercal sensory system of the cricket, Gryllus bimaculatus. J Comp Physiol [A] 162:573-579.

Katz B, Miledi R (1968) The role of calcium in neuromuscular facilitation. J Physiol (Lond) 195:481-492.

Katz PS, Kirk MD, Govind CK (1993) Facilitation and depression at different branches of the same motor axon: evidence for presynaptic differences in release. J Neurosci 13:3075-3089.

Keyser DO, Alger BE (1990) Arachidonic acid modulates hippocampal calcium current via protein kinase $\mathrm{C}$ and oxygen radicals. Neuron 5:545-553.

Killian KA, Murphey RK (1992) Retrograde control of facilitation at an ectopic central synapse. Soc Neurosci Abstr 18:581.

Koerber RH, Mendell LM (1991) Modulation of synaptic transmission at Ia-afferent fiber connections on motor neurons during high-frequency stimulation: role of the postsynaptic target. J Neurophysiol 65:590-597.

Korn H, Faber DS (1991) Quantal analysis and synaptic efficacy in the CNS. Trends Neurosci 14:439-445.

Korn H, Faber DS, Burnod Y, Triller A (1984) Regulation of efficacy at central synapses. J Neurosci 4:125-130.

Kuno M (1964) Mechanisms of facilitation and depression of the excitatory synaptic potential in spinal motor neurons. J Physiol (Lond) 175:100-112.

Landis SC (1990) Target regulation of neurotransmitter phenotype. Trends Neurosci 13:344-350.

Levine RB, Truman JW (1982) Metamorphosis of the insect nervous system: changes in morphology and synaptic interactions of identified neurons. Nature 299:250-252.

Lin J-W, Faber DS (1988) Synaptic transmission mediated by single club endings on goldfish Mauthner cell. II: Plasticity of excitatory postsynaptic potentials. J Neurosci 8:1313-1325.

Malinow R (1991) Transmission between pairs of hippocampal slice neurons: quantal levels, oscillations, and LTP. Science 252:722-724.

Malinow R, Tsien RW (1990) Presynaptic enhancement shown by whole-cell recordings of long-term potentiation in hippocampal slices. Nature 346:177-180.

Mallart A, Martin AR (1968) The relation between quantum content and facilitation at the neuromuscular junction of the frog. $J$ Physiol (Lond) 196:593-604.

Manabe T, Renner P, Nicoll RA (1992) Postsynaptic contribution to long-term potentiation revealed by the analysis of miniature synaptic currents. Nature 355:50-55.

Martin AR (1966) Quantal nature of synaptic transmission. Physiol Rev 46:51-66.

Muller KJ, Nicholls JG (1974) Different properties of synapses between a single sensory neuron and two different motor cells in the leech CNS. J Physiol (Lond) 238:357-369.

Odell TJ, Hawkins RD, Kandel ER, Arancio O (1991) Tests of the roles of two diffusible substances in long-term potentiation: evidence for nitric oxide as a possible early retrograde messenger. Proc Natl Acad Sci USA 88:11285-11289.

Ohmori H, Rayport SG, Kandel ER (1981) Emergence of post-tetanic potentiation as a distinct phase in the differentiation of an identified synapse in Aplysia. Science 213:1016.

Pawson PA, Chase R (1988) The development of transmission at an identified molluscan synapse. I. The emergence of synaptic plasticities. J Neurophysiol 60:2196-2210.

Rahamimoff R (1968) A dual effect of calcium ions on neuromuscular facilitation. J Physiol (Lond) 195:471-480.

Rayport S, Camardo JS (1984) Differential emergence of cellular mechanisms mediating habituation and sensitization in the developing Aplysia nervous system. J Neurosci 4:2528-2532.

Shepherd D, Murphey RK (1986) Competition regulates the efficacy of an identified synapse in crickets. J Neurosci 6:3152-3160.

Shepherd D, Kamper G, Murphey RK (1988) The synaptic origins of receptive field properties in the cricket cercal system. J Comp Physiol $162: 1-11$

Shimozawa T, Kanou M (1984) The aerodynamics and sensory physiology of range fractionation in the cercal filiform sensilla of the cricket Gryllus bimaculatus. J Comp Physiol [A] 155:495-505.

Weeks JC, Jacobs GA (1987) A reflex behavior mediated by mono- 
synaptic connections between hair afferents and motor neurons in the larval tobacco hornworm Manducca sexta. J Comp Physiol 160:315329.

Wernig A (1972) Changes in statistical parameters during facilitation at the crayfish neuromuscular junction. J Physiol (Lond) 226:751759 .

Wojtowicz JM, Atwood HL (1986) Long-term facilitation alters trans- mitter releasing properties at the crayfish neuromuscular junction. $\mathbf{J}$ Neurophysiol 55:484-498.

Zoran MJ, Doyle RT, Haydon PG (1991) Target contact regulates the calcium responsiveness of the secretory machinery during synaptogenesis. Neuron 6:145-151.

Zucker RS (1973) Changes in the statistics of transmitter release during facilitation. J Neurophysiol 35:621-637. 